\title{
A PARTICIPAÇÃO dA ASSOCIAÇÃO BRASILEIRA DE ENFERMAGEM - SEÇÃO DE MINAS GERAIS, NOS EXAMES DE SUPLENCIA PROFISSIONALIZANTE - HABILITAÇÃO TECNICO DE ENFERMAGEM*
}

\author{
** Aguida Stemler de Oliveira \\ Maria José da Silva \\ Nair Rodrigues da Cunha
}

\begin{tabular}{l|c|}
\cline { 2 - 2 } & $\mathrm{RB} / 04$ \\
\hline
\end{tabular}

OLIVEIRA, A.S., SILVA, M.J. e CUNHA, N.R.- A participação da Associação Brasileira de Enfermagem. Rev. Bras. Enf.; DF, 30 : 93-107, 1977.

\section{I - INTRODUÇÃO}

A UTRAMIG - Fundação de Educação para o Trabalho de Minas Gerais, entidade responsável pela preparação dos programas de exames e elaboração das provas do Projeto Acesso - Exames de Suplência Profissionalizante, do Departamento de Ensino Supletivo do Ministério da Educação e Cultura, por sugestão de uma nossa associada, em agosto de 1973, convidou a Senhora Presidente da A.B.En. - M. G., para participar da organização dos citados exames, na modalidade Técnico de Enfermagem.

Era um projeto pioneiro do D.E.Su/ M.E.C., em caráter experimental nos estados de Minas Gerais e Pernambuco e no Distrito Federal, com a finalidade de desenvolver programas de exames $\mathrm{Su}$ pletivos em modalidades técnicas, a nivel de 2. ${ }^{\circ}$ grau.

Deste modo, a Presidente e a Coordenadora da Comissão de Educação da A.B.En. - M.G., iniciaram os contatos com a Equipe Técnica da UTRAMIG, procurando conhecer o Projeto Acesso, seus objetivos, especialmente a metodologia de trabalho empregada na formulação de programas e exames e na elaboração dos diversos modelos de provas.

Ao mesmo tempo, solicitamos a colaboração da A.B.En. -- Nacional, através de contatos com a Presidente e com a Coordenadora da Comissão de Educação, e ainda com a Irmã Maria Turkiewicz, devido a sua experiência com Curso Técnico de Enfermagem, em Curitiba.

\footnotetext{
- Tema Livre apresentado no XXVIII CBEn - RJ.

* Presidente da ABEn - Seção de Minas Gerais.

* Coordenação da Comissão de Educação da ABEn - MG e Diretorora da Faculdade de Enfermagem da UCMG.

**** Professora da Faculdade de Enfermagem da UCMG.
} 
A função a desempenhar era importante, e, sentimos a enorme responsabilidade na definição de critérios para a elaboração de programas e provas das disciplinas constantes do elenco da Habilitação Técnica de Enfermagem. Daí, procuramos nos entrosar com as Escolas de Enfermagem das Universidades Federal e Católica de Minas Gerais, solicitando a indicação de professores das diversas disciplinas, e assim, constituimos uma Comissão e trabalhamos conjuntamente com a equipe técnica da UTRAMIG.

Além da coordenação dessa comissão, participamos de reuniōes diversas, com representantes da UTRAMIG, das Secretarias de Educação dos estados de Pernambuco e Minas Gerais, da Fundação Educacional do Distrito Federal e com a Diretora do Departamento de Ensino Supletivo do Ministério da Educação e Cultura.

Tudo isto, exigiu muito esforço e dedicação de todos os participantes, em vista da experiência de trabalho, das reuniōes constantes e prolongadas, muitas vezes acaloradas, mas que proporcionaram um vercadeiro enriquecimento para todos.

\section{II - PROJETO ACESSO - SUPLENCIA PROFISSIONALIZANTE:}

O Ensino Supletivo, já estabelecido no país com a finalidade de suprir a escolarização regular para adolescentes e adultos, cada vez mais, oferece oportunidades a um grande número de pessoas, de retomar seus estudos, independentemente de seguir o processo regular do sistema educacional, e de dar continuidade em outros niveis do sistema, a seus estudos interrompidos por razōes diversas, inclusive pela impossibilidade de o sistema educacional atender à cres- cente demanda de ensino em suas diferentes formas e graus.

Entretanto, no campo do desempenho profissional, um contingente significativo de pessoas se encontrava em atividades técnicas, com capacidade adquirida mediante a experiência de trabalho, aguardando uma oportunidade de reconhecimento legal. Numa pesquisa sobre a seleção de supervisores de nível médio, realizada em área industrial do estado de Minas Gerais, com a cooperação da empresa tradicional do parque siderúrgico nacional, revelou que no universo em estudo, $45 \%$ dos supervisores apresentavam idade compreendida entre 21 e 35 anos, e apenas $37 \%$ da população pesquisada, era portadora de diploma de técnico de nível médio.

Na indústria de São Paulo, o quadro levantado não difere substancialmente do acima apontado, pois revela a existência de elevado contingente de técnicos em serviço, sem a devida habilitação profissional.

Todas estas situações, confirmadas e estendidas a outras regiōes do país, poderá apresentar um quadro distorcido ou mais sério ainda, mesmo levando em conta a carência estatística para uma avaliação global.

Em vista desta situação, é que surgiu a iniciativa do estabelecimento de exames para modalidades técnicas a nível de $2 .^{\circ}$ grau, capazes de promover a avaliação e de conferir habilitação profissional às pessoas já engajadas em atividades econômicas, nas modalidades definidas pelo Conselho Federal de Educação.

Então, constatada a realidade dos quadros profissionais e demonstrada a aprovação por parte dos escalōes superiores do Sistema Educacional, o Departamento de Ensino Supletivo do M.E.C., anteviu a possibilidade de ser concretizada 
sua antiga aspiração, qual seja, a de desenvolver um sistema que permitisse a criação de exames de suplência para a área profissionalizante, oferecendo oportunidades a todos aqueles que já incorporados às atividades econômicas e exercendo atividades técnicas, pudessem pleitear seu reconhecimento legal para efeito de habilitação profissional.

Assim surgiu o Projeto Acesso - Exames de Suplência Profissionalizante a nível de 2.0 grau, fundamentado legalmente na Lei n.o 5.692/71 - artigo 16 , 24 e 26; e Pareceres números 45/72 e $659 / 72$, do Conselho Federal de Educação, elaborado pelo Departamento de Ensino Supletivo do M.E.C., com os seguintes objetivos:

1. ${ }^{\circ}$ Promover exames de suplência nas modalidades técnicas constantes do Parecer n. ${ }^{\circ}$ 45/72 do Conselho Federal de Educação, a pessoas sem a devida escolaridade, na área profissionalizante.

2.) Desenvolver programas de exames de suplência profissionalizante a nível de $2 .^{\circ}$ grau, em caráter experimental nos estados de Minas Gerais e Pernambuco e no Distrito Federal.

3. ${ }^{\circ}$ Unificar as diretrizes e processos de desenvolvimento da atividade, através do D.E.Su./M.E.C.

4. ${ }^{\circ}$ Promover social e economicamente, as pessoas profissionalmente capazes e que estejam exercendo suas funções em empresas e instituições.

Em vista da realização de exames de suplência profissionalizante a nível técnico de $2 .^{\circ}$ grau, os Conselhos Estaduais de Educação de Minas Gerais e Pernambuco fixaram normas sobre os mesmos, segundo as diretrizes do Projeto Acesso - D.E.Su./M.E.C., e o Distrito Federal se orientou pelo referido projeto.

Para a inscrição de candidatos, foram determinados os seguintes pré-requisitos:
- maior de 21 anos (com nível ou sem nível de escolaridade);

- declaração de empresa ou instituição onde trabalha ou trabalhou, comprovando o exercício presente ou passado na profissão a que se habilita (mínimo de 2 a 3 anos);

- comprovação de residência na área de jurisdição do estado.

E para planejar e implantar experimentalmente, em coordenação com os sistemas de ensino, programas de exames de suplência profissionalizante a nível técnico de $2 .^{\circ}$ grau, segundo as modalidades previstas pelo Conselho Federal de Educação, foi organizado um sistema, composto de quatro sub-sistemas, assim discriminados:

1 - Subsistema de elaboração - para preparação dos programas dos exames e elaboração dos modelos de provas, a cargo da UTRAMIG;

2 - Subsistema de coordenação - visando uma ação unificada de aplicação e correção das provas do exame supletivo, nas diversas modalidades técnicas, a cargo do D.E.Su./M.E.C.;

3 - Subsistema de aplicação - para a realização das provas, designação e orientação dos componentes das equipes de aplicadores, a cargo das Secretarias Estaduais de Educação e da Fundação Educacional do Distrito Federal.

4 - Subsistema de resultados - destinado a correção das provas e avaliação dos resultados, oferecendo elementos para a emissão dos devidos certificados ou diplomas de habilitação, também a cargo dos sistemas de ensino.

III - SUPLENCIA PROFISSIONALIZANTE - TECNICO DE ENFERMAGEM

\section{1 - Considerações Gerais:}

Em nossos primeiros contatos com a UTRAMIG, procuramos estudar o Proje- 
OLIVEIRA, A.S., SILVA, M.J. e CUNHA, N.R. - A participação da Associação Brasileira de Enfermagem. Rev. Bras. Enf.; DF, 30 : 93-107, 1977.

to Acesso - D.E.Su./M.E.C., sua fundamentação legal, seus objetivos, especialmente, a organização do sistema destinado a planejar e implantar experimentalmente os exames de suplência profissionalizante, tendo em vista, a definição de critérios para a elaboração dos programas e das provas para a modalidade enfermagem.

Passamos então a analisar a formação do Técnico de Enfermagem, a mais nova categoria ocupacional da equipe de enfermagem e ainda não regulamentada por lei, que acrescida da grande carência de pessoal habilitado, torna-se difícil de identificar o seu desempenho básico e as suas tarefas típicas no exercício da profissão. A situação da enfermagem é bem diferente das demais modalidades, pois conta com o Auxiliar de Enfermagem, cuja formação vem sendo realizada há bem pouco tempo, com suas atribuiçōes regulamentadas legalmente.

Assim levantamos algumas objeçōes nestes exames, especialmente no tocante à inscrição, sem exigência do nível de escolaridade; e da comprovação do exercício na enfermagem, podendo haver o risco das declaraçōes indevidas, muitas vezes, pelo desconhecimento das atividades típicas. E como o Auxiliar de Enfermagem vem pleiteando uma possibilidade de acesso a Técnico de Enfermagem, poderia ser essa uma oportunidade de promoção desses elementos, que a nosso ver, desempenha atividades próprias de técnicos, além de uma grande maioria possuir a formação geral do $2 \circ$ grau. Contudo, verificamos a impossibilidade de se organizar exames específicos para a habilitação enfermagem bem como de poder limitar as inscriçōes apenas aos Auxiliares de Enfermagem.
Pois o Projeto Acesso já havia sido elaborado, e pelas suas diretrizes, os Conselhos Estaduais de Educação fixaram normas sobre exames supletivos para exclusivo efeito de habilitação profissional a nível de $2 .^{\circ}$ grau, especialmente 0 de nosso estado, definidas de acordo com a Resolução n. ${ }^{\circ}$ 172/73, de 21 de setembro de 1973.

Em vista desta realidade, sentimos que era nosso dever cooperar nessa experiência, pois em caso contrário, seria uma omissão de nossa parte.

\section{2 - Desenvolvimento dos trabalhos:}

A nossa atividade inicial consistiu na preparação dos programas das disciplinas constantes do elenco da habilitação enfermagem, seguida da elaboração das respectivas provas escritas, em cooperação, pela Comissão de professores de enfermagem, de acordo com as suas especialidades, e assessorada por técnicos da UTRAMIG, segundo os moldes formulados pelo sistema.

Estabelecemos os critérios para as provas escritas e teórico práticas, atribuindo o valor total em 1.000 (mil) pontos; sendo 700 (setecentos) ou $\mathbf{7 0 \%}$ para as provas escritas e $\mathbf{3 0 0}$ (trezentos) ou $\mathbf{3 0 \%}$ para a teórico prática. Estipulamos para aprovação, o mínimo de $50 \%$, ou seja, 350 (trezentos e cinqüenta) pontos para as escritas e 150 (cento e cinqüenta) para a teórico prática. As provas escritas eram eliminatórias e somente se inscrevia para a prova teórico prática, os candidatos habilitados nas provas escritas.

Foi a seguinte, a distribuição dos pontos por provas:

a) Provas escritas: Total -700 pontos $=\mathbf{7 0 \%}$ 
OLIVEIRA, A.S., SILVA, M.J. e CUNHA, N.R. - A participação da Associação Brasileira de Enfermagem. Rev. Bras. Enf.; DF, 30 : 93-107, 1977.

Discriminação:

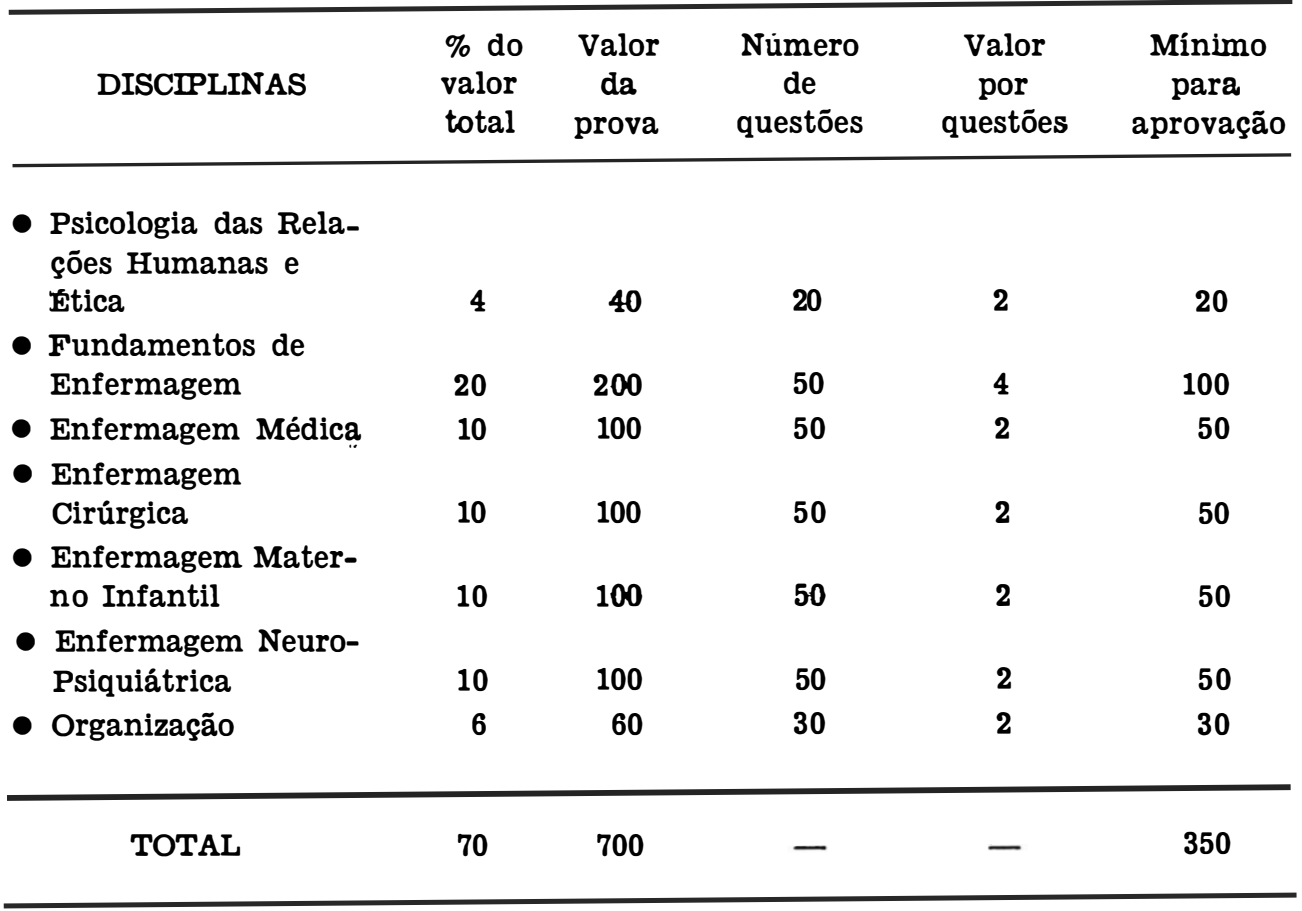

b) Provas teórico práticas: Total 300 pontos $=30 \%$

Discriminação:

Desempenho da prática -240 pontos Relatório da técnica executada - 60 pontos

TOTAL 300 pontos

Realizadas as provas escritas, participamos com a equipe técnica da UTRAMIG, com os representantes dos Sistemas de Ensino e com a Diretora do D.E.Su./M.E.C., da avaliação dos resultados de correção das provas.

Prosseguimos na preparação das provas teórico práticas, quando encontramos as maiores dificuldades, em vista do número de habilitados, do tempo previsto para a realização destas provas e principalmente, de que modo se processaria a avaliação do desempenho de- monstrado pelos candidatos durante a prática.

Levantamos 50 (cinqüenta) técnicas de enfermagem, especificando o material necessário e as condiçōes requeridas para a execução das mesmas, quando verificando a impossibilidade de incluir todas no programa das provas teórico práticas em razão das dificuldades encontradas, concluimos por selecionar 16 (dezesseis) dessas técnicas, que consideramos básicas na organização destas provas.

Para a realização das provas teórico práticas num final de semana, em três turnos horários, estabelecemos as condições exigidas quanto a local, material e equipamentos, e definimos as comissōes examinadoras.

Estas comissões, constituídas de duas docentes de enfermagem e coordenadas por uma das participantes da comissão de elaboração das provas, em número de 
OLIVEIRA, A.S., SILVA, M.J. e CUNHA, N.R. - A participação da Associação Brasileira de Enfermagem. Rev. Bras. Enf.; DF, $30: 93-107,1977$.

três por sistema de ensino, funcionaram concomitantemente. Cada examinando dispunha de 20 (vinte) minutos, cronometrados, para a execução da técnica sorteada e de 30 (trinta) minutos para o relatório da mesma, podendo estimar o número de candidatos por turno e por comissão - Anexo I.

Assim, no ato da inscrição, o candidato recebia a indicação do dia, local e turno em que faria a prova, o que facilitou o andamento dos trabalhos, evitando aglomeração de candidatos e favorecendo ainda aos que se encontravam em serviço.

Com o objetivo de unificar a sistemática de aplicação das provas teórico práticas nas três unidades da federação, elaboramos um modelo para o examinando relatar a técnica executada Anexo II; Uma ficha para o examinador avaliar o desempenho do examinado - Anexo III; além das seguintes instruções para os examinadores:

1..$^{\circ}$ Sorteada a técnica pelo examinando, um dos examinadores (de cada comissão), deverá anotar no modelo de relatório:

- nome e número de inscrição do candidato; no cabeçalho)

- material solicitado pelo mesmo para a execução da técnica sorteada (no item 3).

Depois de rubricado pelos examinadores, este modelo será entregue ao monitor responsável pelo preparo do material, que entregará ao candidato o que foi requisitado - Anexo II.

2. $)^{-}$Enquanto o monitor seleciona o material requisitado, os examinadores arguirão o examinando a respeito da técnica a ser executada, anotando as observações no ítem 9 - Área cognitiva da ficha de avaliação - Anexo III.

Para isso, cada examinador tomará uma ficha de avaliação, onde anotará o nome do examinando e o seu próprio nome (no cabeçalho); e no decorrer da prova, enquanto observa o examinando, irá registrando com um $X$, de acordo com os ítens das áreas e as colunas indicadas, o valor correspondente a cada aspecto analisado. Anexo III.

Visando facilitar a avaliação do candidato em relação ao ítem 9 nesta ficha, elaboramos questões em formas de problemas, baseadas nas técnicas indicadas. Para cada técnica, elaboramos três questões-problemas com as respectivas respostas, as quais dependendo da técnica sorteada e com o tempo previsto para a sua execução, serão testadas uma ou duas questões ao examinando, podendo ainda cada examinador acrescentar outras, desde que dentro do assunto da técnica sorteada.

3.0) Em seguida o examinando executará a técnica, observado pelos examinadores, que registrarão na ficha individualmente os pontos correspondentes aos aspectos avaliados nas áreas motoracognitiva (exceto o item 9) e afetiva, correspondentes às colunas e aos itens indicados nesta ficha.

Ao terminar, cada examinador já deverá ter atribuído os pontos alcançados pelo examinando. Anexo III.

4.) Finalmente, o examinando fará o relatório da técnica executada no modelo com a sua identificação e rubricado pelos examinadores, dentro do prazo determinado. - Anexo II.

Os pontos da prova teórico prática serão atribuídos do seguinte modo:

a) no desempenho da técnica, cada examinador atribuirá os pontos respectivos em cada ficha de avaliação Anexo III, marcando-se com um $X$ nos quadros correspondentes aos aspectos analisados nas três áreas e aos pontos graduados nas colunas; sendo 16 aspectos e os pontos graduados de 1 a 5 , 0 total de pontos é obtido assim:

$16 \times 5=80 \times 1,5$ (peso) $=120 \times 2$ examinadores) $=240$. 
OLIVEIRA, A.S., SILVA, M.J. e CUNHA, N.R.-A participação da Associação Brasileira de Enfermagem. Rev. Bras. Enf.; DF, 30 : 93-107, 1977.

b) na confecção do relatório, o coordenador (especialista participante da elaboração das provas), atribuirá os pontos segundo as especificações constantes no modelo: parte I - ítens de 1 a 6 , valor de 40 pontos; e parte II - descritiva, valor de 20 pontos, perfazendo então 60 pontos os quais somados aos 240 pontos, completam os 300 pontos referentes ao valor desta prova - Anexos I e II.
3 - Candidatos inscritos e aprovados nos sistemas:

De acordo com os dados constantes do Relatório Final da UTRAMIG sobre a aplicação dos Exames de Suplência profissionalizante, nas 15 modalidades técnicas, realizadas em Pernambuco, Minas Gerais e no Distrito Federal, em janeiro de 1975, o maior número de candidatos inscritos foi para Enfermagem, atingindo $65 \%$ dos totais, em números absolutos.

ENFERMAGEM - CANDIDATOS INSCRITOS E APROVADOS

Sistemas

Inscritos

Aprovados

$\%$

Pernambuco

Minas Gerais

Distrito Federal
546

384

406
76

105

89
13,9

27,3

21,9

TOTAL

1.336

270

20,2

Os candidatos habilitados nos Exames de Suplência Profissionalizante, quando portadores de certificados de conclusão do ensino de $2 .^{\circ}$ grau (antigo $2 .^{\circ}$ ciclo), receberão o competente Diploma de Técnico.

Os que não tiverem estudos ao nível de $2^{\circ}$ grau, obterão um Certificado que os credenciará a exercer a atividade técnico profissional.

Os diplomas e certificados, de acordo com os modelos especiais, serão registrados nos Órgãos competentes do Sistema de Ensino.

\section{ENFERMAGEM - TOTAL DE DIPLOMAS E CERTIFICADOS}

Sistemas

Pernambuco

Minas Gerais

Distrito Federal
Certificados

48

39

49
Diplomas

Total

76

105

89 
OLIVEIRA, A.S., SILVA, M.J. e CUNHA, N.R. - A participação da Associação Brasileira de Enfermagem. Rev. Bras. Enf.; DF, $30: 93-107,1977$.

\section{IV - CONCLUSÃO}

A nossa participação no Projeto Acesso, de outubro de 1973 até maio de 1975, iniciada com a preparação de programas e provas escritas e teórico prática, terminou com a Coordenação da aplicação destas provas em Recife, Brasília e Belo Horizonte, e a devida avaliação dos resultados.

O Projeto Acesso abriu novas perspectivas no campo da educação técnica e da formação profissional, com a aplicação dos Exames de Suplência Profissionalizante, os quais, após um estudo mais aprofundado, poderão oferecer Subsídios ao sistema regular de ensino além das oportunidades de retorno aos estudos e da complementação dos conhecimentos adquiridos no campo de trabalho.

Achamos a experiência válida para a enfermagem, que conta com um grande contingente de pessoal sem a devida habilitação exercendo atividades profissionais, especialmente quando estamos empenhados em disciplinar o exercício da profissão no país.

Como este trabalho nos possibilitou um conhecimento mais detalhado das atividades desenvolvidas numa experiência inédita em termos de exames supletivos de habilitação profissional a nível técnico de $2 .^{\circ}$ grau, Julgamos por bem trazê-lo ao conhecimento dos colegas, recomendando:

- que os enfermeiros procurem conhecer a legislação que dispõe sobre a suplência profissionalizante, para assim poderem oferecer assessoramento aos orgãos estaduais de ensino na organização desses exames nos respectivos estados.

\section{V - REFERENCIAS BIBLIOGRAFICAS}

1. BRASIL, Ministério da Educação e Cultura; Departamento de Ensino Supletivo. Suplência Profissionalizante; exames. Brasilia, Departamento de Documentação e Divulgação, 1974.

2. BRASIL, Ministério da Educação e Cultura; Departamento de Ensino Supletivo. Suplência Profissionalizante; Sistema de Registro de Diplomas $e$ Certificados. Brasília, Departamento de Documentação e Divulgação, 1974.

3. BRASIL, Ministério da Educação e Cultura; Departamento de Ensino Supletivo. Suplência Profissonalizante; exames, forma de consecução. Brasília, Departamento de Documentação e Divulgação, 1974.

4. BRASIL, Ministério da Educação e Cultura; Departamento de Ensino Supletivo. Suplência Profissonalizante; programas. Brasilia, Departamento de Documentação e Divulgação, 1974.

5. BRASIL, Leis, decretos, etc. - Habilitaçōes profisisonais no ensino do $2 .^{\circ}$ grau. Brasilia, Expressão e Cultura, 1972.

6. BRASIL, Ministério da Saúde. Fundação Serviços de Saúde Pública. Enfermagem, Legislação e Assuntos correlatos. 3.a ed. Rio de Janeiro, 1974.

7. BRASIL, Ministério da Saúde, Secretaria Geral. Catálogo Brasileiro das principais ocupaçōes do Setor Saúde. Rio de Janeiro, 1972.

8. BRASIL, Ministério da Educação e Cultura; Departamento de Ensino Supletivo; Projeto Acesso. Relatório Final. Belo Horizonte, UTRAMIG, 1975. (mimeografado). 


\section{ANEXO I}

\section{MINISTÉRIO DA EDUCAÇÃO E CULTURA - MEC/DSU EXAME DE SUPLENCIA PROFISSIONALIZANTE PROVA TEÓRICO-PRÁTICA — TÉCNICO DE ENFERMAGEM}

1. LOCAL - As provas Teórico-Práticas deverão ser realizadas em Escolas de Enfermagem ou de Técnico de Enfermagem em laboratório devidamente equipado.

2. REALIZAÇÃO DAS PROVAS - As provas Teórico-Práticas serão prestadas perante 3 (três) Comissões Examinadoras, constituídas por 2 (dois) docentes de Enfermagem, cada um indicado pelo Diretor do Estabelecimento homologado e de 1 (um) especialista que participou da Comissão de elaboração de provas.

2.1. As provas Teórico-Práticas envolverão conhecimentos básicos para o suficiente desempenho das funções técnicas, contendo questões relacionadas com as disciplinas de enfermagem, envolvendo a utilização de material com interpretação específica das seguintes técnicas:

- Cama com paciente

- Higiene oral

- Temperatura, pulso, respiração

- Pressão arterial

- Curativo simples

- Curativo umbelical

- Injeção subcutânea

- Injeção intradérmica

- Injeção intramuscular

- Injeção intravenosa

- Soroterapia

- Lavagem externa

- Posição para exames

- Aplicações quentes

- Colocar e retirar comadre e compadre (marreco)

- Massagem de conforto

OBSERVAÇAO: Em cada técnica enfatizar os princípios científicos não só nas questōes como também na execuçāo.

2.2. As provas Teórico-Práticas terão a duração máxima de 20 (vinte) minutos por candidato.

2.3. Realizada a prova Teórico-Prática, o candidato deverá elaborar um relatório, tendo 30 minutos para isso. 
2.4. Ao término das provas Teórico-Práticas será lavrada ata contendo:

- Total de candidatos inscritos

- Total de candidatos que compareceram

- Nome dos componentes das Comissōes Examinadoras

- Outras ocorrências que se tenham verificado.

Essa ata deverá ser assinada pelos componentes das Comissões Examinadoras. Cópia da ata deverá ser anexada juntamente com as fichas de avaliação individual, relatório e lista de presença assinada pelos candidatos.

\section{INSTRUÇÕES AOS EXAMINADORES}

Os examinadores indicados para participar das Comissōes receberão instruções prévias do especialista que os colocará a par dos critérios que serão adotados na aplicação das provas Teórico-Práticas.

3.1. Os examinadores deverão verificar com antecedência se os laboratórios das Escolas indicadas para as provas Teórico-Práticas estão devidamente equipados com o material necessário para a execução das técnicas programadas.

3.2. E da competência dos examinadores, após a orientação do especialista, o preparo do material com a devida antecedência, para que haja maior aproveitamento do tempo previsto.

3.3. Os examinadores deverão comparecer ao local indicado para realização das provas, no mínimo 20 minutos antes do início das mesmas.

3.4. As provas Teórico-Práticas terão a duração máxima de 20 minutos por candidato.

3.5. A técnica para a prova Teórico-Prática deverá ser sorteada pelo candidato.

3.6. O candidato requisitará o material necessário, o qual deverá ser anotado pelos examinadores (ver Relatório), e entregue ao candidato para executar a técnica.

Observar o preparo e desempenho da técnica e anotar os resultados na ficha de avaliação individual do candidato.

3.7. A cada candidato deverá ser entregue, ao término da prova TeóricoPrática, o roteiro para a confecção do relatório.

3.8. Compete ao examinador atribuir notas de 1 a 5 , de acordo com a ficha de avaliação individual do candidato, sendo anotado com um $X$, à tinta, na coluna correspondente a cada aspecto da área observada.

OBSERVAÇÃO: 1. A nota da prova Teórico-Prática será atribuída pelos dois examinadores de cada Comissão e a nota final do candidato será: a soma das notas dos examinadores mais a nota do relatório. 
2. No resultado final o candidato poderá perfazer 300 pontos, sendo o mínimo de 150 pontos para ser aprovado.

1. VALOR DA PROVA TEORICO-PRATICA $\ldots \ldots \ldots \ldots \ldots \ldots \ldots . \ldots 240$ pontos

2. VALOR DO RELATORIO $\ldots \ldots \ldots \ldots \ldots \ldots \ldots \ldots \ldots \ldots \ldots \ldots \ldots$ pontos

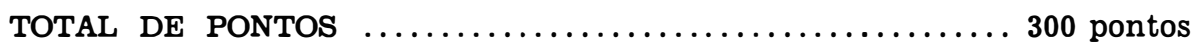

I P A R T E

VALOR DOS ITENS DO RELATÓRIO

1. Nome da Técnica

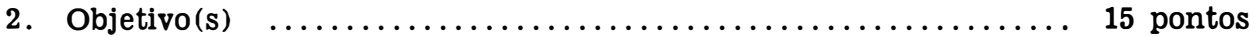

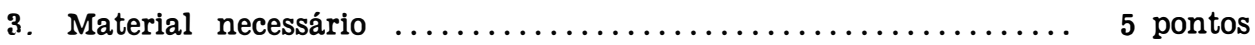

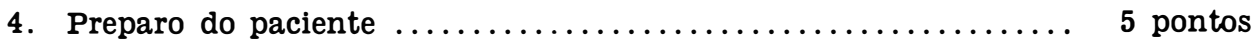

5. Cuidado posterior com o material .................. 10 pontos

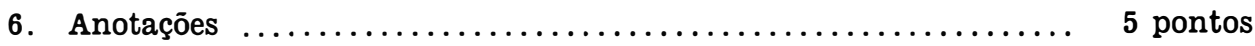

I I P A R T E

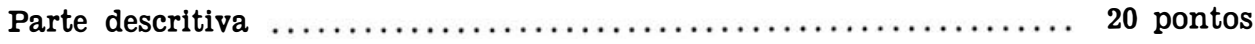

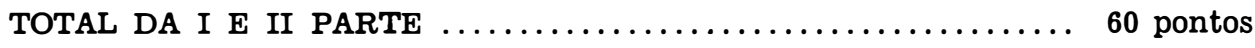




\section{ANEXO II}

\section{MINISTÉRIO DA EDUCAÇÃO E CULTURA DEPARTAMENTO DE ENSINO SUPLETIVO SECRETARIA DE EDUCAÇÃO TÉCNICO DE ENFERMAGEM - RELATORIO}

NOME DO CANDIDATO

N. ${ }^{\circ}$ DE INSCRIÇAO:

A primeira parte deste Relatório está relacionada com a técnica sorteada pelo candidato para a prova Teórico-Prática.

I P A R T E

1. NOME DA TECNICA EXECUTADA:

2. OBJETIVO(S) (Citar qual ou quais as finalidades da técnica executada):

3. MATERIAL NECESSARIO UTILIZADO (preenchido pelo examinador conforme solicitação do candidato): 
4. PREPARO DO PACIENTE:

5. CUIDADO POSTERIOR COM O MATERIAL:

6. ANOTAÇOES (Citar os aspectos que julgar mais impotantes na Técnica) : 


\section{I P R T E}

A segunda parte deste Relatório está relacionada com o Setor de Saúde onde você exerce suas atividades.

1. NOME DA INSTITUIÇÃO ONDE TRABALHA:

2. SETOR DE ATUAÇÃ:

3. DESCREVER no máximo de 10 a 15 linhas o trabalho que realiza:

LOCAL E DATA:

NOME DO CANDIDATO:

N. ${ }^{\circ}$ DE INSCRIÇAO: 


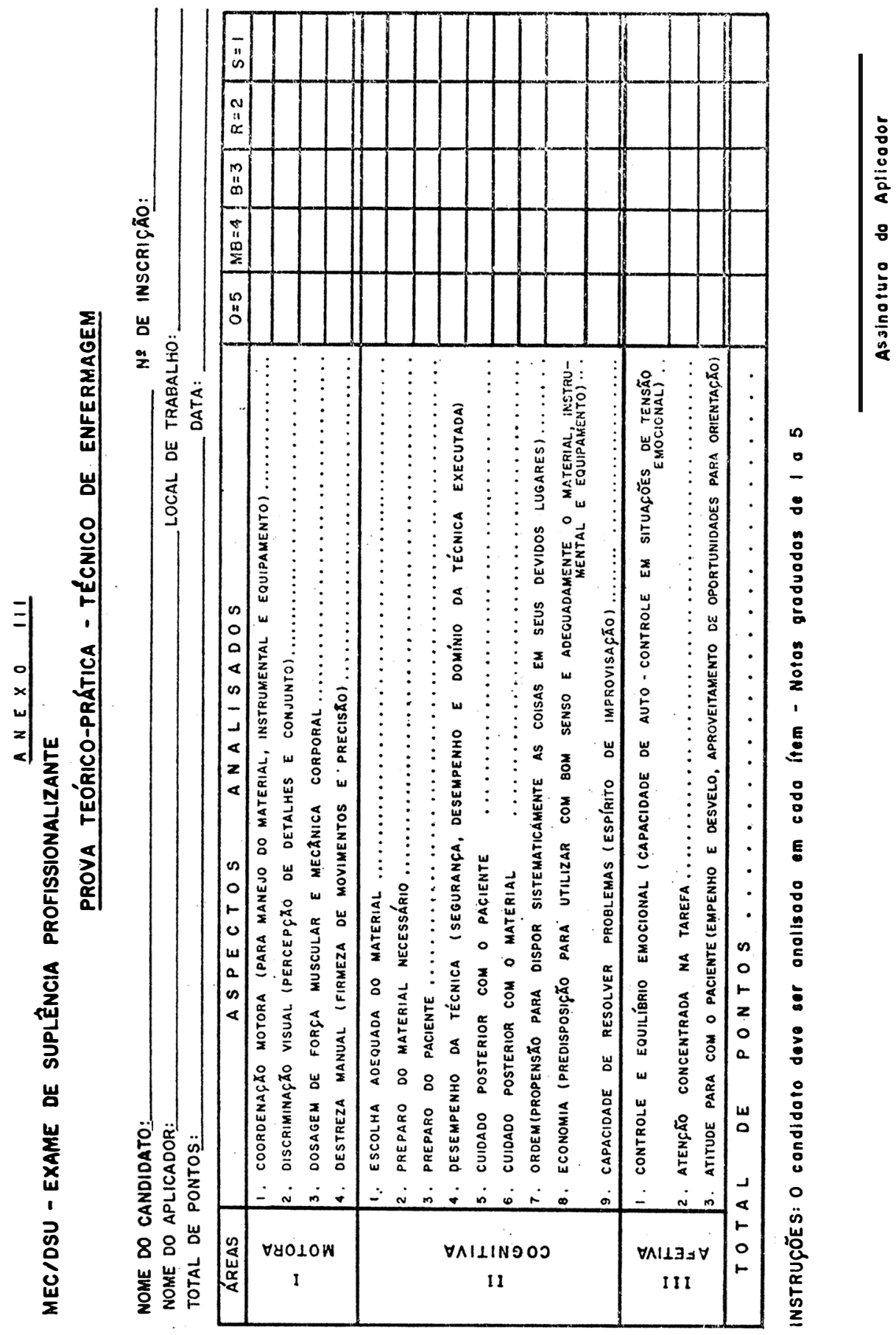

